\title{
EFEITOS DE MOVIMENTOS SOCIAIS NO CICLO DE POLÍTICAS PÚBLICAS
}

\author{
Euzeneia Carlos* \\ Monika Dowbor* * \\ Maria do Carmo Albuquerque ***
}

\begin{abstract}
Analisa os efeitos políticos de movimentos sociais no ciclo de políticas públicas, por meio de estudo comparativo nos setores de direitos humanos, de criança e adolescente, e de saúde. A pesquisa empírica compara seis campanhas ao longo de duas décadas (1990 e 2000), desencadeadas pelos movimentos sociais correlatos através de documentos e entrevistas com ativistas. Utiliza abordagem correlacional como lógica de mensuração das consequências políticas, ou seja, a correspondência entre as demandas dos movimentos nas campanhas e os efeitos na política setorial. O estudo classifica os efeitos políticos associados às campanhas de movimentos na tipologia de ciclo de políticas públicas. A principal contribuição é demonstrar a influência de movimentos sociais nas diferentes etapas do ciclo de políticas, sejam eles formação de agenda, especificação de alternativas, decisão ou implementação, cujos efeitos são produzidos pelas condições referidas aos movimentos e ao Estado, tais como repertórios, coalizões e capacidades estatais.
\end{abstract}

Palavras-chave: Movimentos Sociais. Políticas Públicas. Efeitos Políticos. Direitos Humanos.

\section{INTRODUÇÃO}

As transformações sociais e políticas que ocorreram no país nas últimas décadas e as dinâmicas de interação entre movimentos sociais, o Estado, as instituições participativas e as agências de políticas estiveram combinadas às campanhas de movimentos e redes de ativismos e, mais recentemente, às ondas de protestos, chamando atenção para uma compreensão mais profunda das consequências de movimentos sociais nas mudanças social e política. Esta agenda de pesquisa prefigurou-se

* Universidade Federal do Espírito Santo (UFES)

Avenida Fernando Ferrari, 514, Campus de Goiabeiras, Goiabeiras. Cep: 29075-910. Vitória - Espírito Santo - Brasil.euzeneiacarlos@gmail.com

https://orcid.org/0000-0003-0553-2746

* * Universidade do Vale dos Sinos (Unisinos)

Avenida Unisinos, 950, Bairro Cristo Rei. Cep: 93022-750.

São Leopoldo - Rio Grande do Sul - Brasil. mdowbor@ gmail.com

https://orcid.org/0000-0002-1845-046X

* * * Centro Brasileiro de Análise e Planejamento (Cebrap). Rua Morgado de Mateus, 615, Vila Mariana. Cep: 04015051. São Paulo - São Paulo - Brasil. mcarmoa@gmail.com https://orcid.org/0000-0003-3026-3429

As autoras agradecem ao Conselho Nacional de Desenvolvimento Científico e Tecnológico (CNPq) e a Fundação de Amparo à Pesquisa e Inovação do Estado do Espírito Santo (FAPES), pelo auxílio concedido por meio dos editais Universal 14/2014 e Universal 06/2014. no contexto de transição do regime autoritário brasileiro da década de 1980, inquirindo o papel dos movimentos sociais na democratização (Dagnino, 1994). Todavia, no país, a temática ascendeu a tal proeminência somente na última década. A preocupação com as mudanças sociais e políticas associadas aos movimentos sociais fincou agenda de pesquisa própria na Europa e nos Estados Unidos, e hoje constitui um campo de investigação em franca expansão. Esses estudos têm demonstrado consequências de movimentos sociais nos campos político e social, mesmo que os resultados na política sejam parciais ou restritos a alguns setores públicos. De modo geral, os estudos sobre as consequências ${ }^{1}$ de movimentos sociais ampliaram seu escopo incorporando os efeitos sociais, culturais, políticos, institucionais e no mercado (Bosi; Giugni; Uba, 2016). Este artigo compartilha do pressuposto de que movimentos sociais importam para os resultados (outcomes) políticos no Estado e nas políticas públicas, podendo produzir efeitos distributivos e ampliar a institucionalização de direitos.

${ }^{1}$ Neste artigo, usamos resultados, efeitos e consequências como sinônimos. 
Entre os resultados de caráter político em relação ao Estado, os estudos internacionais assinalam as mudanças nas políticas públicas, no processo legislativo, nas burocracias, na extensão dos direitos, nos partidos políticos e nos regimes (Amenta et al., 2010; Bosi; Giugni; Uba, 2016). No Brasil, as mudanças políticas associadas aos movimentos sociais foram identificadas em diferentes arenas, processos políticos e setores públicos, como no legislativo (Maciel, 2011), no abolicionismo (Alonso, 2014) e nas políticas públicas (Carlos, 2021; Dowbor; Carlos; Albuquerque, 2018; Tatagiba; Teixeira, 2016;). Ainda que os avanços sejam significativos, as questões sobre como movimentos importam em comparação com outros determinantes das mudanças políticas não têm sido conclusivas (Amenta et al., 2010; Bosi; Giugni; Uba, 2016).

Neste artigo, buscamos contribuir com essa agenda de pesquisa explorando o modo como os movimentos sociais afetam as políticas públicas e seus efeitos sobre elas, por meio de estudo comparativo de seis campanhas desencadeadas nos anos 1990 e 2000, nos setores de direitos humanos, de criança e adolescente e de saúde. A pesquisa empírica é inovadora ao introduzir a campanha como unidade de análise de movimento social, comumente estudado a partir de suas organizações ou dos ativistas. Isso é particularmente útil para operacionalização empírica do conస్ ceito de movimento social como rede de inteN rações informais entre uma pluralidade de indivíduos, grupos e/ou organizações engajados ๙े em um conflito político ou cultural com base ริ em identidades compartilhadas (Diani, 2003). $\therefore$ Analiticamente, a campanha permite caracteलि rizar o movimento em seu processo de ação no $\vec{i}$ continuum temporal, conduzindo à investigação longitudinal das consequências políticas de movimentos sociais. Rejeitando qualquer tipo de causalidade permanente, o artigo utiliza uma abordagem correlacional (Bosi, 2016) como lógica de mensuração dos efeitos, ou seja, a correspondência entre os clamores do movimento social nas campanhas e os resultados na política setorial.

Inquirindo sobre as condições que favorecem os resultados alcançados nas políticas, este estudo explora algumas dimensões dos movimentos sociais e do Estado que operam de modo combinado (Amenta et al., 2010; Giugni; Yamasaki, 2009). Em particular, analisa comparativamente como o repertório de interação, as coalizões de defesa e as capacidades estatais na política setorial se combinam na explicação dos efeitos de movimentos sociais.

Identificamos os efeitos de movimentos sociais nas políticas classificando-os nas etapas do ciclo de políticas públicas (Kingdon, 1995; Souza, 2006). Em geral, a literatura aponta que os efeitos de movimentos nas políticas são percebidos, sobretudo, nas etapas iniciais, ou seja, na formulação da agenda, na especificação de alternativas e na tomada de decisões. Em estudo anterior, demonstramos que movimentos sociais influenciam na origem de políticas públicas, particularmente na especificação de alternativas, quando instrumentos de políticas adotados pelos gestores possuem sua gênese em inovações sociais produzidas por movimentos sociais e reconhecidas pelos tomadores de decisões como alternativa de políticas (Dowbor; Carlos; Albuquerque, 2008). Nesse sentido, argumentamos que os movimentos sociais produzem resultados em diferentes etapas do ciclo de políticas - formação de agenda, especificação de alternativas, decisão política e implementação - influenciando a criação de órgãos públicos e colegiados, normativas e legislações, planos e programas que engendram capacidades estatais na burocracia governamental. As condições dos movimentos sociais e do Estado operam de modo combinado na produção dos efeitos políticos, relacionando de modo interdependente os repertórios, as coalizões e o grau de institucionalização da política.

$\mathrm{O}$ artigo segue estruturado em quatro sessões, além desta introdução e da conclusão. A primeira apresenta a literatura especializada 
nos temas de consequências políticas de movimentos sociais e ciclo de políticas públicas, com ênfase nos tipos de consequências e nos seus modelos combinados. A segunda descreve o desenho de pesquisa comparativo, o método de análise temporal e correlacional, e os procedimentos metodológicos, além das principais categorias analíticas. A terceira sessão apresenta as seis campanhas de movimentos ao longo do tempo, identificando seus objetivos no contexto de emergência. Analisa os repertórios de interação, as coalizões de defesa e as capacidades estatais, apontando as principais recorrências e diferenças. Por fim, a quarta parte discute os efeitos dos movimentos sociais nas políticas públicas nas áreas de direitos humanos, criança e adolescente e saúde, classificando seus resultados nas etapas do ciclo de políticas públicas.

\section{CONSEQUÊNCIAS DE MOVIMEN- TOS SOCIAIS E EFEITOS NAS POLÍTICAS PÚBLICAS}

As perguntas em que medida e como movimentos sociais importam têm norteado as pesquisas sobre as consequências políticas de movimentos sociais. Incipiente até os anos 1990, o campo se renovou com estudos de diferentes tipos de efeitos de movimentos, permitindo indagar sob quais condições os movimentos sociais produzem certos resultados, como emblematizado na coletânea How social movements matter, organizada por Giugni, McAdam e Tilly (1999). Os estudiosos focaram em três tipos de efeitos: biográficos, culturais e políticos (Amenta et al., 2010; Earl, 2004; Giugni, 2008). Recentemente, ampliaram a agenda de pesquisa englobando as consequências sociais, culturais, institucionais, políticas e no mercado, como na obra exemplar The consequences of social movements, editada por Bosi, Giugni e Uba (2016).

Na coletânea organizada pelos autores, as novas questões são distribuídas em três agrupamentos: indivíduos, instituições e políticas (Bosi; Giugni; Uba, 2016). No primeiro (indivíduos), além das consequências biográficas nos ativistas, os autores destacam os efeitos na população em geral, podendo engendrar processos amplos de mudança social e cultural. Assinalam, ainda, que ativistas na burocracia pública com trajetória no movimento podem afetar a mudança política e social (Banaszak, 2010) ou quando ativistas entram nos partidos políticos (Rootes, 2004). Também são investigados os efeitos na ação coletiva, nos enquadramentos interpretativos, nos discursos, nas táticas, na organização e nas identidades (Polleta; Jasper, 2001).

No segundo (instituições), as consequências de movimentos sociais na mudança institucional são enfatizadas e podem ser analisadas de três formas: i) como consequência cultural de movimentos; ii) como mudança incremental nas relações de poder, na sequência de instituição formal e informal ou na mudança de normas (Mahoney; Thelen, 2009); e iii) como transformação abrupta de organizações, mudança de regimes ou mudanças políticas significantes durante momentos de crise (Bosi, 2016). Dentre esses, as consequências de movimentos na legislação se destacam, especialmente na inclusão do conteúdo do seu clamor na agenda legislativa e na aprovação de projetos de lei (Amenta et al., 2010). Ao mesmo tempo, os trabalhos sobre a influência de protestos na mudança na burocracia do Estado têm sido menos frequentes, assim como os efeitos de movimentos no sistema de partidos e nos regimes políticos, a exemplo de Piccio (2016), que investiga os impactos da ecologia de movimentos nos partidos.

Por fim, o terceiro agrupamento (políticas) se vincula às consequências de movimentos examinadas neste artigo, em termos de políticas públicas. Os resultados de movimentos sociais nas políticas públicas são examinados sobretudo nas diferentes etapas da política (policy making), afetando ambas as elites e as políticas (Bosi; Giugni; Uba, 2016). Nesse aspecto, 
os estudos mostram que movimentos sociais são mais efetivos na etapa de formação da agenda (agenda setting) e de formulação da política (policy formation), sendo menos influentes nas etapas de adoção e implementação de políticas (Soule; King, 2006; Amenta et al., 2010).

Por outro lado, alguns estudos observam a influência de movimentos na etapa de implementação, a exemplo da política ambiental, seja garantindo a execução de legislação, seja impedindo sua adoção ou programa indesejável (Rootes; Nulman, 2015). Igualmente, os estudos de Banaszak (2010) sobre as táticas do movimento feminista demonstram sua influência nos resultados das políticas para as mulheres, criando oportunidades para impactar diferentes etapas do ciclo de políticas públicas. Desse modo, movimentos também podem influenciar a implementação de políticas públicas, além das etapas iniciais do ciclo de políticas.

A literatura sobre modelos de análise dos efeitos políticos dos movimentos sociais nas políticas públicas se concentrou nas condições sob as quais os movimentos produzem certos resultados. No primeiro momento, foi assinalado que a estrutura de mobilização (estratégias e forma organizacional) dos movimentos sociais condicionava os resultados políticos (Gamson, 1990)..$^{2}$ No segundo momento, ponderou-se que os movimentos sociais operam influenciando a opinião pública e contando com as oportunidades políticas a seu favor.

নิ Sua mobilização, se combinada com o clima ○ propício na sociedade, influenciaria a ação dos políticos que detêm a atribuição e o poder de ๙े transformar as demandas e reivindicações em จิ políticas públicas (Giugni, 2008). Para o autor, $\dot{2}$ alianças poderosas tanto dentro quanto fora de க் arenas institucionais e a existência de redes

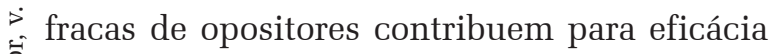
do movimento social. Avanços seguintes nessa literatura apontaram que a estrutura de mobilização dos movimentos e a sua interação com

${ }^{2}$ Para uma revisão ampliada da literatura internacional sobre os modelos explicativos dos efeitos políticos de movimentos sociais, ver Carlos, Dowbor e Albuquerque (2017). o contexto político operam, de modo combinado, na explicação dos efeitos políticos da ação coletiva, constituindo o chamado "modelo combinado" (Giugni, 2008; Giugni; Yamasaki, 2009). Por seu turno, as conexões entre as condições explicativas dos efeitos foram enfatizadas no "modelo de mediação política", ou seja, a interdependência entre certas formas de organização e estratégias e alguns contextos políticos (Amenta et al., 2010). A combinação de condições não implica que exista uma forma organizacional, estratégia ou contexto político que sempre produzam resultados políticos. Os autores defendem que os movimentos adquirem influência quando adaptam suas estratégias e formas organizacionais ao contexto político específico. Importante inflexão ocorreu nos modelos ao se deslocar da noção imprecisa de oportunidade política para a categoria de Estado, que inclui o nível de democratização, o sistema partidário no poder e o grau de desenvolvimento da burocracia em torno da política pública almejada (Amenta et al., 2010).

\section{O ciclo de políticas públicas}

As definições de políticas públicas enfatizam diversos aspectos, dentre os quais, as ações e escolhas de governo que influenciam a vida dos cidadãos e envolvem embates e conflitos entre ideias, preferências e interesses de grupos dentro e fora do governo (Souza, 2006, p. 6). As diversas abordagens que analisam a produção de políticas públicas apontam para as configurações múltiplas de atores envolvidos nas etapas do ciclo de políticas públicas: 1) a definição da agenda pública; 2) a especificação de alternativas; 3) a decisão política; e 4) a implementação da política. ${ }^{3}$ Kingdon (1995) identifica os atores visíveis e invisíveis de maneira detalhada nas etapas de formação de agenda e especificação de alternativas. Para a formação de agenda, o esquema analítico de

\footnotetext{
3 Além dessas etapas do ciclo de políticas, Souza (2006) identifica as fases de avaliação e de monitoramento.
} 
Kingdon permite identificar três fluxos (problema, solução e política), cuja convergência em janela de oportunidade faz um dado problema subir para a agenda governamental. Os atores do movimento têm aqui um espaço para a atuação ao colocar energia na construção do problema, divulgando dados e informações e acompanhando criticamente a atuação. A especificação de alternativas consiste na apresentação por diversos atores de propostas e soluções para um dado problema que está na agenda de governo (Capella, 2018). Os políticos e gestores públicos, com base em critérios políticos e técnicos, cotejam as propostas e cabe a eles a tomada da decisão de implementar uma delas. Assim, a decisão política ocorre nos distintos âmbitos da federação (União, estado ou município) e esferas de poder (Legislativo ou Executivo) por meio de leis, decretos, portarias etc. A fase de implementação é vista majoritariamente na perspectiva multicêntrica (Secchi, 2010), ou seja, podendo contar com os atores oriundos das três esferas, setor público, privado e sociedade civil. Ocorre no território através de instrumentos de políticas, ou seja, técnicas e dispositivos que permitem materializar e operacionalizar a ação governamental, tais como metodologias, critérios de contratação, currículo mínimo, formulários para monitoramento, bancos de dados, planos, programas.

O ciclo de política pública é um modelo de análise que permite distinguir etapas ou fases na produção da política, embora não sequenciais ou estanques, mas articulados num processo dinâmico (Souza, 2006). Além disso, as diferentes fases do ciclo de políticas podem ser analisadas com uma lente maior ou menor, de forma que os instrumentos não estão aprisionados na execução local da política. A definição de um currículo ou a constituição de um banco de dados, por exemplo, podem ser instrumentos para a operacionalização de uma política no âmbito nacional ou municipal, mas também podem integrar o momento decisório numa fase posterior ou anterior de operacionalização da política.

\section{Desenho de pesquisa, método e categorias analíticas}

Esta pesquisa se baseia no método de estudos de casos comparados (Gerring, 2007), aplicado a processos de interação entre movimentos sociais e Estado com objetivo de influenciar a produção de políticas públicas. Os casos consistem em seis campanhas empreendidas por três movimentos sociais (Movimento de Direitos Humanos, Movimento da Criança e Adolescente e Movimento de Saúde), em três níveis da federação (municipal, estadual e federal) e três setores de políticas públicas correlatas, método vantajoso para investigar as consequências políticas (Bosi; Guigni; Uba, 2016).

As campanhas ocorreram no contexto de redemocratização posterior à Constituição Federal de 1988 (CF/88) e se originaram em diferentes níveis da federação, conquanto alçando abrangência nacional. Foram protagonizadas por movimentos sociais históricos, com legado de experiências pretéritas e aprendizados nas trajetórias, com expertise em setores de políticas específicas. Contudo suas diferenciações quanto ao tipo de movimento e setor de política guardam importantes implicações, especialmente quanto aos repertórios, às coalizões e às capacidades estatais na política pública. Essas similitudes e distinções são consideradas no desenho de pesquisa, para aferir os efeitos dos movimentos nas políticas públicas e explorar como os movimentos produzem certos resultados.

A pesquisa empírica introduziu "campanha" como unidade de análise de movimento social. A campanha é um momento de visibilidade pública da ação do movimento, formada por conjunto de eventos e episódios com sequenciamento concatenados e constituintes do processo de ação coletiva (Tilly, 2006). Trata-se de categoria mais abrangente do que "ciclo de protestos", pois a este não se limita e é mais restrita do que movimento social, na medida em que este pode contemplar diferentes cam- 
panhas em sua trajetória. É um esforço público sustentado de elaboração de reivindicações coletivas direcionadas a determinadas autoridades (Tilly, 2010). Adotar campanha permite apreender o movimento social ao longo de um continuum temporal, que se inicia com a formulação de um objetivo político claro e se desdobra num processo no qual se (re)constroem as identidades, (re)criam as organizações, os repertórios, as redes e coalizões, convergindo num conjunto de interações.

O exame dos i) efeitos das campanhas de movimentos sociais nas políticas públicas; e das ii) condições combinadas que operam nos resultados políticos foi instrumentalizado a partir de dois enfoques complementares. Primeiro, por meio da abordagem correlacional de consequências políticas (Bosi, 2016), os objetivos das campanhas foram associados aos resultados alcançados correlacionalmente, e não causalmente, ou seja, buscando a correspondência entre as reivindicações dos movimentos nas campanhas e os resultados na política setorial. Os resultados no ciclo de políticas foram observados desde a formação de agenda, a especificação de alternativas e a decisão política até a implementação. Segundo, por meio dos modelos combinado (Giugni e Yamasaki, 2009) e de mediação política (Amenta et al., 2010), analisamos sob quais condições os movimentos sociais produzem os resultados. Buscando as conexões entre dimensões dos moviনี mentos e do Estado, ressaltamos três condições i. que agem de modo combinado, quais sejam, o repertório de interação, as coalizões de defesa సิ e as capacidades estatais na política setorial.

Na primeira, usamos o conceito de "re¿. pertórios de interação" (Abers; Serafim; Tatagi§i ba, 2014), originário do conceito de repertório $\dot{\Delta}$ tillyano, ou seja, "conjunto de performances reivindicatórias, historicamente criado, limitado e familiar, que circunscreve geralmente as formas pelas quais as pessoas se engajam na política contenciosa” (Tilly, 2006, p. vii). Ressaltamos nos repertórios, por um lado, as ações institucionais e extrainstitucionais (Car- los, 2015; Dowbor, 2012); por outro, os padrões de interação com o Estado (cooperativo, conflitivo ou cooperação-conflitual), reconstruindo-os longitudinalmente(Carlos, 2015, 2017). ${ }^{4}$

Na segunda, o conceito de "coalizão de defesa" (Sabatier; Weible, 2007) nos auxiliou a inquirir com quem os atores do movimento se articularam nos momentos de densidade e visibilidade da campanha. As coalizões de defesa são formadas por múltiplos atores (sociais e institucionais) que compartilham crenças acerca de um setor de política pública, projetos específicos ou programas dos governos, produzindo aumento substantivo da rede de aliados. Por fim, na dimensão do Estado, a institucionalização da política pública é examinada por meio das capacidades estatais, ou seja, o conjunto de instituições e burocracias que favorece a ação governamental em setores de políticas. Nas capacidades estatais, são considerados os aspectos técnico-administrativos (legislação e normativas, órgãos e instituições, financiamento e burocracia) e político-relacional (conselhos, conferências e outros colegiados) (Pires; Gomide, 2016). ${ }^{5}$

A coleta de evidências empíricas se baseou em entrevistas semiestruturadas em profundidade com ativistas dos movimentos e, em poucos casos, também com agentes estatais (26 no total); análise documental em documentos de época de organizações dos movimentos; e fontes secundárias sobre os casos. A sistematização das informações coletadas em entrevistas e documentos, que consistem numa grande

4 "O padrão de interação cooperativo dos movimentos com a esfera estatal é caracterizado pelo estabelecimento de relações de colaboração e parceria na elaboração de políticas públicas e na implementação e execução de projetos e programas específicos do governo" (Carlos, 2017, p. 337338). Ao passo que a cooperação conflitual considera que os movimentos sociais são ambivalentes e utilizam uma estratégia de combinação entre o conflito e a cooperação; com isso, "conjectura a permanência do conflito nas interações de cooperação com o Estado” (p. 340).

5 A dimensão técnico-administrativa "envolve as capacidades derivadas da existência e funcionamento de burocracias competentes e profissionalizadas, dotadas dos recursos organizacionais, financeiros e tecnológicos necessários para conduzir as ações de governo de forma coordenada”. A político-relacional é associada a "habilidades e procedimentos de inclusão de múltiplos atores visando à construção de consensos mínimos e coalizões de suporte" às políticas governamentais (Pires; Gomide, 2016, p. 127). 
quantidade de dados qualitativos (269 documentos, contabilizando cerca de cinco mil páginas), foi auxiliada pelo uso do Software NVivo Pro 11. O Quadro 1 apresenta as campanhas dos movimentos sociais, o período de duração, o nível da federação e os setores de políticas. surge o Centro de Apoio aos Direitos Humanos (CADH) e o Conselho Estadual de Direitos Humanos (CEDH), além de entidades religiosas, sindicatos trabalhistas e ONGs que compõem a rede do movimento. O MDH-ES desenvolveu campanhas nacionais contra diversas formas

Quadro 1 - Movimentos sociais, campanhas e setores de políticas públicas (1990 e 2000)

\begin{tabular}{|c|c|c|c|c|}
\hline Movimentos Sociais & Campanhas & Período & Nível da federação & $\begin{array}{l}\text { Setor de } \\
\text { política }\end{array}$ \\
\hline \multirow{2}{*}{$\begin{array}{l}\text { Movimento de } \\
\text { Direitos } \\
\text { Humanos }\end{array}$} & 1. Impunidade e Corrupção & 1993 a 2002 & \multirow{2}{*}{ Estadual (ES) } & \multirow{2}{*}{$\begin{array}{l}\text { Direitos } \\
\text { humanos }\end{array}$} \\
\hline & 2. Violações no Sistema Prisional & 2003 a 2012 & & \\
\hline \multirow{2}{*}{$\begin{array}{l}\text { Movimento pelos } \\
\text { Direitos da Criança e } \\
\text { Adolescente }\end{array}$} & 3. Sistema Febem & 1995 a 2007 & \multirow{2}{*}{$\begin{array}{l}\text { Estadual } \\
\text { e Municipal (SP) }\end{array}$} & \multirow{2}{*}{$\begin{array}{l}\text { Criança e } \\
\text { adolescente }\end{array}$} \\
\hline & $\begin{array}{l}\text { 4. Política Socioeducativa em Meio } \\
\text { Aberto }\end{array}$ & 1999 a 2010 & & \\
\hline \multirow[b]{2}{*}{ Movimento de Saúde } & 5. Financiamento da Saúde Pública & 2003 a 2012 & \multirow[b]{2}{*}{ Nacional } & \multirow[b]{2}{*}{ Saúde } \\
\hline & $\begin{array}{l}\text { 6. Recursos Humanos para Saúde } \\
\text { Pública }\end{array}$ & 1997 a 2001 & & \\
\hline
\end{tabular}

Fonte: Elaboração própria com base na pesquisa.

\section{REPERTÓRIOS, COALIZÕES E CAPACIDADES ESTATAIS NAS CAMPANHAS DE MOVIMENTOS SOCIAIS}

Nesta sessão, descrevemos as seis campanhas empreendidas pelos três movimentos sociais, nas décadas de 1990 e 2000, identificando seus objetivos no contexto de emergência, dando ênfase aos repertórios de interação e as coalizões de defesa, combinados às capacidades estatais na política setorial.

\section{Campanhas do Movimento de Direitos Hu- manos}

O Movimento de Direitos Humanos no Espírito Santo (MDH-ES) possui um histórico de lutas sociais que remonta à década de 1980, com a criação, em 1984, do Centro de Defesa de Direitos Humanos da Serra (CDDH-Serra) e do Movimento Nacional de Direitos Humanos (MNDH-Leste I). Na década de 1990, de violência institucionalizadas ao longo de décadas, sobressaindo em termos de mobilização, longevidade no tempo e capacidade de ressonância. ${ }^{6}$

A "Campanha Contra a Impunidade e Corrupção" foi lançada no dia 19 de agosto de 1993 na cidade de Vitória (ES). A campanha foi criada pelo Movimento Nacional de Direitos Humanos (MNDH), a partir de suas bases no MDH-ES articulado no MNDH-Leste I e no CDDH-Serra. Com quase uma década de duração, a campanha se estendeu até 2002. As denúncias de crime organizado infiltrado nas instituições do Estado e de atuação de grupos de extermínio foram as principais motivações para emergência da campanha. Seu objetivo político se vinculava à uma situação notável de impunidade, corrupção e violência expressa nos assassinatos impunes de ativistas e lideranças partidárias e sindicais, no extermínio de crianças e adolescentes e um grande nú${ }^{6}$ Para um exame detalhado da Campanha Contra a Impunidade e Corrupção e da Campanha Contra as Violações no Sistema Prisional do MDH-ES, a partir da análise das oportunidades e restrições políticas e dos repertórios de confronto, e dos mecanismos que operam nesta dinâmica, ver Carlos (2021). 
mero de homicídios encobertos e sem investigação policial. Associado à ação de grupos de extermínio como a Scuderie Detetive Le Cocq (SDLC), a campanha clamava pelo combate ao crime organizado penetrado no Estado (Executivo, Legislativo e Judiciário).

Ao longo da campanha o movimento, notabilizou-se pela sua capacidade organizativa, de posicionamento político e de investigação independente. Acionou múltiplos repertórios de interação, combinando ação extrainstitucional e institucional. As ações extrainstitucionais predominantes na campanha correspondem a iniciativas do movimento em defesa da causa, composta por relatório, banco de dados, dossiê, denúncia, fórum, divulgação na mídia, passeata, ato público, vigília e carta aberta. Ao passo que as ações institucionais consistem em repertórios que acionam partes do Estado, formadas por abertura de Comissão Parlamentar de Inquérito (CPI), relatórios, diagnósticos e denúncias por agentes estatais apoiadores, reuniões com autoridades, pedido de intervenção federal, ação civil pública, conselhos de políticas, lobby e ocupação de cargos. As relações entre movimento e Estado configuraram dois padrões de interação socioestatal, sendo o conflitivo e o cooperação-conflitual acionados circunstancialmente no confronto político.

Em sua origem, a campanha sustentou-se na articulação de uma rede de movimento com cerca de 40 entidades estaduais (organizaస్ర ções de movimentos sociais, entidades religioi. sas, sindicatos trabalhistas, ONGs e ativistas), promotoras do Fórum das Entidades do Campo e da Cidade e do Fórum Contra a Violência em ণิ Defesa da Vida (Carlos, 2014). Ao passo que, $\therefore$ no momento de maior visibilidade e pico de ஸే mobilização, formou-se uma ampla coalizão de

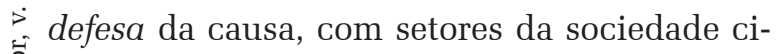
vil e da sociedade política, articulando atores e instituições no nível nacional e internacional.

F Constituída no Fórum Permanente Contra a Violência e a Impunidade "Reage Espírito Santo", a coalizão reuniu em ações coordenadas diversas organizações civis e religiosas, parti- dos políticos, órgãos governamentais (Secretaria Estadual de Justiça e Cidadania - Sejuc, Conselho Nacional dos Direitos da Pessoa Humana - CDDPH), Legislativo Federal, Ordem dos Advogados do Brasil (OAB-ES), Ministério Público Federal (MPF), ONG Justiça Global e organizações intergovernamentais, como a Organização dos Estados Americanos (OEA).

Por seu turno, a "Campanha Contra as Violações no Sistema Prisional” emergiu no Espírito Santo, em 2003, motivada pelo lançamento da Campanha Nacional Permanente Contra Tortura promovida pelo MNDH, em colaboração com a Secretaria Especial dos Direitos Humanos da Presidência da República (SEDH-PR). A campanha nacional (2001 a 2003) enquadrou os casos de "tortura institucional" e os associou às agências de segurança pública, como as secretarias estaduais de justiça, responsáveis pela administração carcerária e as polícias civil e militar (Movimento Nacional de Direitos Humanos, 2003, p. 6). A campanha foi promovida no ES por organizações do movimento de direitos humanos (MNDH-Leste I, CDDH-Serra, CADH e Justiça Global), entidades da Igreja Católica (Pastoral do Menor e Pastoral Carcerária) e do CEDH. A campanha se prolongou por uma década, com desfecho em 2012.

O objetivo político da campanha foi a defesa dos direitos dos sujeitos privados de liberdade em oposição a violência ilegal do Estado, este percebido como oponente, pois responsável pelos tratamentos cruéis e degradantes nas prisões e Unidades de Internação Sócioeducativa (Unis). As denúncias de violência institucionalizada se reportavam aos estabelecimentos penais, intensificadas no período de 2006 a 2010 (CEDH, 2011). As constantes denúncias de tortura, esquartejamento, superlotação e outras violações revelavam um sistema calamitoso que foi comparado nas inúmeras inspeções e diligências aos "campos de concentração nazista" e às "masmorras da idade média”. As violações nas prisões se estendiam às Unis, constatadas pelo Conselho Nacional dos Direitos da Criança e do Adolescente (Co- 
nanda), após denúncias de tortura e morte de adolescentes (Carlos, 2015, p. 239).

Ao longo da campanha, uma diversidade de repertórios de interação foram acionados, composto por ações extrainstitucionais e institucionais, com leve predomínio das extrainstitucionais. Estas correspondem a denúncia, visitação, ato público, divulgação na mídia, vigília, passeata, ocupação, paralisação, fiscalização, apelo e abaixo-assinado. Por meio do repertório de ação institucional, foram realizados relatórios, diligências, reuniões com autoridades, audiências públicas, CPI, lobby e petição pública. Nos padrões de interação socioestatal se ressalta o conflitivo, seguido pela cooperação-conflitual por meio do qual o movimento aciona o apoio de instituições políticas ao mesmo tempo que mantem a atitude de contestação na relação com o Estado.

A rede do movimento composta por $\mathrm{CADH}, \mathrm{CDDH}-\mathrm{Serra}$, CEDH, Pastoral do Menor e Carcerária foi amplificada pela coalizão de defesa formada no pico de mobilização. A coalizão envolveu o Legislativo e Executivo Federal (deputados federais e senadores da Comissão de Direitos Humanos, e o CDDPH do Ministério da Justiça), a Associação de Mães e Familiares de Vítimas de Violência do ES (AMAFAVV), tendo alçado a escala internacional por meio da articulação com as ONGs Justiça Global e Conectas Direitos Humanos, e com a Organização das Nações Unidas (ONU) e a Organização dos Estados Americanos (OEA).

\section{Campanhas do Movimento pelos Direitos da Criança e Adolescente}

O Movimento pelos Direitos da Criança e Adolescente (MDCA) se organizou e lutou desde o período constituinte $(\mathrm{CF} / 88)$ pela implantação de um paradigma garantista na atenção à infância, elevando crianças e adolescentes à condição de sujeitos de direitos. ${ }^{7}$ É

${ }^{7} \mathrm{O}$ paradigma garantista se coloca em oposição ao modelo "menorista" ou da "situação irregular", que se refere a um movimento que se organiza em campanhas nas quais se aglutinam organizações que se articulam durante ciclos de mobilização, algumas com maior permanência, como os Fóruns dos Direitos da Criança e Adolescente, presentes nos diversos níveis da federação. Essas organizações são constituídas, em sua maioria, por profissionais defensores dos direitos da infância, tais como assistentes sociais, educadores, psicólogos, pediatras, advogados e juristas, que atuam em organizações sociais como pastorais religiosas e ONGs, ${ }^{8}$ ou mesmo em instituições públicas da educação, saúde, assistência social, sistema de justiça, conselhos tutelares e conselhos de direitos da criança e adolescente. Esses profissionais integraram as organizações do movimento no seu cotidiano e muitos outros compuseram organizações aliadas, que constituíram coalizões de defesa dos direitos da criança e do adolescente.

$\mathrm{Na}$ "Campanha pelo Fim da Febem", o elemento deflagrador mais imediato foram as rebeliões dos adolescentes nas unidades da Febem de São Paulo, nos anos de 1992 a 2002.9 A campanha foi impulsionada, ainda, pelas transformações democráticas no nível internacional com a ratificação do paradigma garantista na Convenção da ONU sobre os Direitos da Infância (CDI), em 1989, e no nível nacional pela incorporação do Art. 227 na CF/88, e aprovação do Estatuto da Criança e Adolescente (ECA), em 1990. As mobilizações que se iniciaram em meados dos anos 1990 se estenderam até 2007 . O objetivo da campanha se expressou na consigna "Pelo fim da Febem" e abrangeu propostas de mudanças institucionais compatíveis com o paradigma garantista, isto é, a dignidade devida a sujeitos de direitos,

"menores" carentes, abandonados e infratores, igualando-os de forma discriminadora.

${ }^{8}$ São exemplos os Centros de Defesa dos Direitos da Criança e Adolescentes (Cedecas) e outros Centros de Defesa de Direitos Humanos com atuação municipal e estadual em São Paulo.

${ }^{9}$ A Febem foi a instituição estadual de internação de adolescentes infratores. A política para adolescentes infratores com privação de liberdade é de competência estadual, enquanto a política em meio aberto é municipal. 
conforme as garantias inscritas no ECA. Entre os objetivos concretos se destacam o direito ao acompanhamento jurídico (devido processo legal) e a adequação das instituições às exigências do ECA, como a salubridade das instalações físicas, o fim dos maus tratos e a oferta de serviços adequados de educação e saúde.

A campanha foi integrada por distintos ativistas e organizações dos direitos da infância, muitos deles integrantes de Cedecas, Centros de Direitos Humanos, pastorais religiosas e associações profissionais. Esses atores construíram uma coalizão de defesa de direitos da criança e adolescente com base em crenças compartilhadas acerca da implementação do paradigma garantista na legislação estadual e nas políticas públicas, outrora mobilizados em torno das normativas internacionais e nacionais. Essa coalizão incluiu diferentes instituições internacionais, nacionais, estaduais e municipais, como o Tribunal dos Povos, a Corte e a Convenção Interamericana dos Direitos Humanos (CIDH) da OEA, as Comissões de Direitos Humanos e dos Direitos da Infância da OAB, da Câmara Federal, da Assembleia Legislativa de São Paulo (Alesp) e da Câmara Municipal em São Paulo, bem como ONGs nacionais como a Conectas Direitos Humanos, Centros de Direitos Humanos estaduais e municipais. Composta por organizações do movimento e apoiadores, a coalizão desenvolveu repertórios de ações conjuntas de forma espeনี cialmente significativa, sobretudo pelo seu po๑ der institucional e simbólico dado pela aliança com atores institucionais. Seus objetivos, essencialmente voltados a mudanças institucio今ึ nais, orientaram a consolidação da coalizão com atores institucionais.

As alianças com atores institucionais viabilizaram a construção de repertórios de ação via instituições, que foram predominantes na campanha (64\%), como as ações por meio de instituições internacionais do sistema ONU (julgamento da Febem pela CIDH/OEA), denúncias apresentadas por procuradores (MP) e juízes, ou via parlamento, especialmen- te através de uma CPI, assim como a atuação por conselhos e conferências participativas. Embora em menor proporção (36\%), os repertórios extrainstitucionais, por exemplo, as visitas à Febem e as denúncias de repressão e violência, se combinaram aos repertórios institucionais visando a eficácia na obtenção dos resultados, cuja interação socioestatal foi fortemente conflitiva.

A "Campanha pela Municipalização das Medidas Socioeducativas em Meio Aberto", ocorrida no município de São Paulo entre 1999 e 2010, também enfocou a construção de instituições garantistas. Seus objetivos se voltam à construção de uma política de atendimento ao infrator, em meio aberto, conforme as diretrizes garantistas definidas no ECA. Estes objetivos abordam dois aspectos: a desinstitucionalização ou redução das instituições fechadas ao mínimo e a criação de um modelo de atendimento ao infrator em meio aberto, próximo de sua família e comunidade (municipalizado), e com perspectiva socioeducativa.

A campanha foi precedida por mobilizações nacionais pela municipalização e pelo meio aberto, inscritas na CF/88, no ECA, na Política Nacional de Assistência Social (PNAS), na Lei Orgânica da Assistência social (Loas) e na normativa de tipificação dos serviços socioassistenciais. Em São Paulo, a emergência da campanha teve como marco a eleição da prefeita Marta Suplicy (Partido dos Trabalhadores - PT), cuja Secretária de Assistência Social, Aldaíza Sposati, era ativista ligada à construção de um sistema descentralizado e municipalizado de Assistência Social, o Sistema Único de Assistência Social (Suas). Paralelamente, o MDCA e uma de suas organizações, a Pastoral do Menor, havia desenvolvido a LAC (Liberdade Assistida Comunitária), cuja experiência deu origem à campanha. A partir das organizações do movimento, a formação de uma articuladora de ONGs denominada "Articulação dos Serviços de Medidas Socioeducativas em Meio Aberto" e a ocupação de cargo na Secretaria de Assistência Social por um ativista dessa ar- 
ticulação favoreceram o desenvolvimento da campanha. Assim, foram integradas à campanha as ONGs já vinculadas ao atendimento em meio aberto, ainda por meio da Febem.

Nesse contexto, a coalizão de defesa da campanha foi formada pelo governo municipal, especialmente a Secretária de Assistência e outros ativistas vinculados às lutas pela municipalização preconizada no Suas. Após um período de sólida aliança com o executivo municipal, seguido de rompimento decorrente das eleições, novos aliados se integram à coalizão, notadamente dos Conselhos $\mathrm{Mu}$ nicipais de Assistência Social (Comas) e dos Direitos da Criança e Adolescente (CMDCA), e integrantes do Departamento de Execuções da Vara Especial da Infância e Juventude (Deij) do Judiciário e do MP.

Esse perfil dos atores favoreceu um repertório de tipo institucional ainda mais predominante $(80 \%)$ do que na campanha anterior, com destaque à participação em conselhos e audiências públicas. Embora em menor proporção, a campanha apoiou-se em repertórios extrainstitucionais, como reuniões de articulação, seminários e grupos de estudos que geraram propostas e modelos de política levados aos conselhos e audiências públicas. Os resultados dependeram da combinação entre esses diferentes repertórios, igualmente à campanha pretérita. No entanto, nesse caso, predominaram as interações cooperativo-conflituais na produção da política de meio aberto. Ambas as campanhas do MDCA são marcadas pela capacidade de ação institucional dos atores do movimento, bem como dos aliados que os apoiaram.

\section{Campanhas do Movimento Nacional de Saúde}

O Movimento Sanitário (ou de Saúde) começou suas primeiras mobilizações no final dos anos 1970 (Escorel, 1998) e se manteve atuante nas três décadas seguintes, engajando-se em diversas campanhas na defesa do siste- ma público, universal, gratuito, integral e participativo de saúde (Dowbor, 2012). Era composto por profissionais de saúde, servidores públicos, professores universitários, estudantes e diversas organizações, dentre as quais a Cebes (1976), a Abrasco (1979), as associações estaduais de secretários municipais de saúde dos anos 1970 e 1980, o Conselho Nacional de Secretários Municipais de Saúde (Conasems) de 1987, a Plenária Nacional de Saúde (1987), a Rede Unida (1996) e o Fórum Brasileiro da Reforma Sanitária (2006). Sua composição e o constante engajamento em diversos momentos da política de saúde permitiu ao movimento acumular as capacidades de mobilização e articulação, bem como de interação com o Estado.

$\mathrm{Na}$ "Campanha pelo Financiamento da Saúde Pública”, desenvolvida de 2003 a 2012, o problema do subfinanciamento foi retratado como o principal obstáculo para o funcionamento pleno do sistema, e a responsabilidade por essa situação era atribuída pelos atores do movimento à queda da participação do governo federal no financiamento da Saúde. Mais especificamente, a "política econômica" e os interesses privados eram apontados como corresponsáveis pela situação desfavorável do setor. O Movimento Sanitário, desde a conquista do Sistema Único de Saúde (SUS) na CF/88, tornou a questão do financiamento do novo sistema algo central para sua implementação. O objetivo central da campanha, tal como atestado nos documentos do início da mobilização, consistiu em garantir uma fonte estável e uma fatia maior do orçamento federal para o setor de saúde por meio da aprovação de uma legislação, acompanhado por dois outros objetivos, o de controle social do orçamento de saúde e de definição dos gastos em saúde. Emergente no contexto de obrigatoriedade legal da regulamentação da Emenda Constitucional 29, em 2003, referente aos recursos para a saúde no nível nacional, o movimento desencadeou a campanha que durou nove anos, focando suas ações primordialmente no âmbito do Poder Legislativo federal. 
No seu repertório de interação, o movimento aproveitou os canais institucionais existentes, mas não abriu mão das mobilizações em formato de protesto, atos públicos e outras formas de demonstrar o comprometimento, os participantes e a causa por meio de manifestações de caráter público. Na campanha como um todo, entre 2003 e 2012, as ações do repertório se distribuíram da seguinte maneira: $60 \%$ eram extrainstitucionais e $40 \%$, institucionais. Delas, $70 \%$ foram de caráter misto, ou seja, orientadas por interação cooperativo-conflitivo, sendo que as interações conflitivas e cooperativas se distribuem quase igualmente nas 30\% restantes. Entre as ações institucionais encontram-se reuniões com autoridades e eventos organizados em parceria com esferas do Estado, como Simpósio no Poder Legislativo e a Caravana da Saúde protagonizada pelo Ministério de Saúde.

Em termos de coalizão de defesa, o movimento recorreu à articulação com outras organizações em apenas dois momentos distintos e pontuais da campanha, a saber: nos momentos de maior visibilidade, em 2006, quando foi montada uma forma organizacional mais ampla e voltada para os objetivos da campanha e, em 2011, no momento de votação da legislação de interesse. A coalizão se restringiu a organizações da sociedade civil como a Confederação Nacional das Associações de Moradores (Conam), a Contag, a CUT e o Moస్․ vimento Popular de Saúde (Mops).

ป $\quad$ Ao passo que a "Campanha pela Formação de Recursos Humanos para Saúde Públi\&े ca” emerge em 1997, no contexto de lançamenণิ to de Edital pela Secretaria de Ensino Superior $\dot{2}$ (SeSu) do Ministério da Educação (MEC), que लि convidava as instituições de ensino superior $\vec{i}$ e as ordens profissionais para a elaboração de propostas de novas diretrizes curriculares. Um ano antes, em 1996, o MEC havia publicado a nova Lei de Diretrizes e Bases da Educação (LDB), que findava a era do modelo de currículos mínimos a serem obrigatoriamente aplicados pelas instituições do ensino superior. A flexibilidade e a flexibilização dos currículos eram as palavras de ordem dessa reformulação, o que permitia aos atores do movimento, tais como a Rede Unida, desenhar os currículos de acordo com sua visão de saúde e necessidades do sistema. O movimento havia desenvolvido, desde os anos 1970, outro modelo de formação voltado para profissionais de saúde pública. Datam da década de 1980 os esforços do movimento para influenciar a educação em saúde, âmbito este tradicionalmente de competência e exclusividade do MEC.

O objetivo central da campanha que se prolongou até 2001 consistiu em incidir na reformulação dos currículos de cursos de graduação possibilitada pela nova LDB. A matriz curricular dos cursos de saúde era até então pautada no modelo flexneriano, ordenado pelo viés técnico, curativo e hospitalocêntrico. A formação proposta pela Rede Unida e seus aliados visava formar um profissional integrado ao SUS, defendendo que uma parte significativa do processo de formação devesse ocorrer nos serviços básicos de saúde, o que contrastava com a ênfase na prática em hospitais do modelo até então em vigência.

Ao longo da campanha, o movimento recorreu a repertórios de interação preferindo os canais institucionais, sendo que, do total de ações registradas, 25\% eram extrainstitucionais e $75 \%$, institucionais. Dentre as ações extrainstitucionais encontram-se os atos públicos e, nas institucionais, a elaboração de propostas de políticas públicas, reuniões com gestores e audiências públicas. As interações foram principalmente de caráter cooperativo-conflitivo e cooperativo, ou seja, sem conflito direto, visando as instâncias decisórias do MEC responsáveis pela elaboração das propostas finais dos currículos.

Da coalizão de defesa fizeram parte desde o início e até o final da campanha as associações de ensino de cursos em saúde, tais como a Associação Brasileira de Enfermagem (ABEn) e a Associação Brasileira de Ensino de Medicina (Abem), bem como Conselhos Na- 
cionais de Secretários de Saúde dos estados e dos municípios (Conass e Conasems) e o Conselho Nacional de Saúde (CNS). Nesse caso, em alguma medida, a coalizão articulou atores da sociedade civil e agentes institucionais.

\section{Capacidades estatais nos setores de políti- cas públicas}

A institucionalização da política pública, enquanto dimensão do Estado que afeta os resultados das campanhas de movimentos sociais, compreende aqui as capacidades estatais para operar a política setorial. No setor de direitos humanos, no estado do Espírito Santo, as capacidades estatais atestam um grau baixo de institucionalização. No período das campanhas, o órgão responsável pelas ações governamentais na área de direitos humanos era a Secretaria Estadual de Justiça (Sejus, antes Sejuc), inexistindo uma burocracia pública e que contemplasse normativas e legislações, planos e programas e financiamento para o setor. Por décadas, o Núcleo de Direitos Humanos (NDH) criado em 1997 no governo Vitor Buaiz (PT) foi o único órgão, acompanhado à época pela criação do CEDH. Com recursos humanos e financeiros deficitários e desacompanhados de política setorial, o NDH se converteu em balcão da cidadania, sendo sua principal função o acolhimento de denúncias de violações no sistema prisional e o suporte ao funcionamento do CEDH. Ressalva importante foi a criação do Cepet, em 2003, e dos programas de proteção às vítimas e testemunhas ameaçadas. No entanto apenas após o desfecho das campanhas, em 2011, a política de direitos humanos se integrou à estrutura administrativa por meio da criação da Secretaria Estadual de Assistência Social e Direitos Humanos e, em 2016, da criação da Secretaria Estadual de Direitos Humanos, cuja burocracia e capacidades estatais estão em fase de estruturação.

Na política de Criança e Adolescente as capacidades estatais foram profundamente afetadas pelas normativas que decorrem da Convenção da ONU sobre os Direitos da Infância (1989), da Constituição Federal (1988) e do ECA (1990). No caso da política para infratores com restrição de liberdade (Febem), o subsetor possuía normativas, regimentos, orçamentos, atribuições, concursos públicos, papeis e relações definidas entre o Executivo e o Judiciário. Porém eram frágeis e insuficientes perante o paradigma de direitos da infância expresso pelas novas legislações, com orçamento reduzido, instalações inadequadas, recursos humanos sem preparo para implementar a perspectiva garantista, falta de normativas, atendimento jurídico, de educação e saúde para os adolescentes. Nesses termos, à época da campanha, a política socioeducativa com privação de liberdade tinha grau médio de institucionalização, dadas as capacidades estatais inadequadas ao paradigma garantista. No entanto, no subsetor de políticas para o infrator no nível municipal e em meio aberto, as capacidades estatais eram inexistentes, indicando um grau baixo de institucionalização da política. O meio aberto existente era vinculado à Febem na esfera estadual, o que gerava alguma capacidade estatal em termos metodológicos, atribuições dos recursos humanos e vinculações com o Judiciário, que puderam ser adaptadas. Inovações sociais desenvolvidas pelo movimento, como a LAC, também aportaram elementos para a construção de capacidades nos municípios, além da existência de conselhos de políticas, como Comas e CMDCA, e da participação de organizações do movimento e ONGs no desenho e na implementação da política.

No caso do setor de saúde, no final dos anos 1990 e no início dos anos 2000, o SUS se encontrava implementado no seu desenho do comando único em cada nível federativo e com as competências definidas, descentralizado e participativo. No que se refere ao conteúdo das políticas mais específicas que as companhas do movimento abordaram, a institucionalização das capacidades era diferente. A decisão sobre a formação de recursos huma- 
nos no nível superior em saúde não pertencia à política setorial de saúde, e sim à pasta do MEC e às legislações dessa área. No caso do financiamento, desde a crise de 1993, o setor vivia um crônico desfinanciamento na medida em que não foi atribuída a ele nenhuma fonte adicional de recursos; ao mesmo tempo, pela primeira vez na história do país, o orçamento da saúde não dependia das contribuições individuais. Assim, do ponto de vista de capacidades estatais, ambas as áreas em questão contavam com grau médio de institucionalização.

\section{Comparando os repertórios, coalizões e capacidades estatais nas campanhas}

Os repertórios, coalizões e capacidades estatais são condições que agem de modo combinado na produção de resultados nas políticas públicas. Os casos apontam a existência de repertórios mistos, de coalizões com atores do Estado e de alianças internacionais e de capacidades estatais com diferentes graus de institucionalização. A análise comparada ressaltou que os movimentos e campanhas utilizaram ambos os repertórios, os institucionais e os extrainstitucionais, embora com variações na sua proporção. No MDCA, por exemplo, as ações institucionais predominam em ambas as campanhas, assim como na segunda campanha do movimento sanitarista; enquanto no $\mathrm{MDH}$ são নิ preponderantes as ações extrainstitucionais ○ nas duas campanhas. Correlato aos repertórios, as interações socioestatais combinam o caráter conflitivo e o cooperativo-conflitual e, no caso dos sanitaristas, também o cooperati$\dot{2}$ vo. De modo geral, os atores do movimento deகீ monstram habilidade de utilizar os canais de

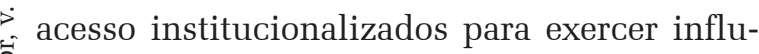
ência nos processos de produção de políticas públicas, o que se deve em parte à sua expertise prévia e aprendizado adquirido em outras campanhas e mobilizações. Ao passo que os repertórios extrainstitucionais são utilizados em geral para pressionar as autoridades a abrir as negociações, diante de constrangimentos de acesso no Estado.

As coalizões de defesa são formadas por múltiplos atores e escalas. Comparativamente, a articulação entre sociedade civil e atores institucionais e a escala internacional foi indicativa de coalizão ampla. As alianças entre organizações sociais e agentes do Estado foi algo comum às coalizões de todas as campanhas, com exceção da campanha pelo financiamento do SUS que se restringiu ao movimento. Além disso, os MDH e MDCA incluíram os organismos intergovernamentais de defesa de direitos como OEA e ONU, alcançando ampla coalizão, menos na campanha pela municipalização da política em meio aberto. As alianças com ONGs internacionais (Justiça Global e Conectas Direitos Humanos) e organismos intergovernamentais podem ser compensatórias das restrições institucionais na arena doméstica.

O grau de institucionalização da política setorial se diferenciou em termos de capacidades estatais, indo das mais frágeis às um pouco mais estruturadas. Além da inexistência de capacidades estatais, como na política estadual de direitos humanos, notam-se as capacidades construídas, porém no sentido oposto ao almejado pelos movimentos, como na campanha pelo fim da Febem e na pela formação de recursos humanos para o SUS, respectivamente nas políticas de DCA e Saúde.

O modo como se combinam essas condições significativas ainda é um desafio que requer a comparação entre maior número de casos, com variação temporal, no tipo de movimento e setor de política. No entanto a comparação entre as campanhas permite apontar algumas tendências ou possibilidades de combinações entre os repertórios, as coalizões e as capacidades estatais com vistas aos resultados nas políticas públicas. A inter-relação entre repertórios e coalizões aponta um achado esperado, qual seja, a existência de coalizões com aliados institucionais aumenta as chances de escolha de repertórios institucionais, que, por seu turno, favorece o aumento das capacidades 
estatais condizentes com os objetivos do movimento. Assim, o repertório institucional do movimento é facilitado pelas alianças institucionais e acessos à burocracia do Estado, como sobressaiu no MDCA e no Sanitário. Por outro lado, a combinação entre repertórios extrainstitucionais e coalizão internacional importa sobretudo para as políticas com capacidades estatais inexistentes, demonstrada no $\mathrm{MDH}$. Nesse caso, as deficiências nas capacidades do Estado podem ter sido contrabalançadas pela combinação entre repertórios extrainstitucionais e coalizão de defesa intergovernamental.

\section{EFEITOS DE MOVIMENTOS SO- CIAIS NO CICLO DE POLÍTICAS PÚBLICAS}

Nesta sessão, discutimos os efeitos dos movimentos sociais no ciclo de políticas públicas nas áreas de direitos humanos, criança e adolescente, e saúde, a partir da correlação com os objetivos das campanhas. No movimento de direitos humanos, a Campanha Contra a Impunidade e Corrupção (1993-2002) colocou na agenda pública o tema do combate à impunidade, à corrupção e à ação do crime organizado. Influenciou na decisão política de investigação das denúncias de crime organizado e grupos de extermínio, como, em 1995, a Representação para Fim de Dissolução da SDLC pelo Delegado de Polícia responsável pelas investigações; em 2000, a inclusão do ES na CPI do Narcotráfico da Câmara Federal; e, em 2002, na instalação da Missão Especial de Combate ao Crime Organizado, do Ministério da Justiça (MJ). Os resultados na política de direitos humanos são expressos na condenação de agentes públicos envolvidos com o crime organizado (2000) e na dissolução da Scuderie Detetive Le Cocq (2004). A campanha também colocou na agenda a fragilidade da burocracia estatal no tema da segurança pública (homicídios, crimes insolúveis ou sem investigação e testemunhas ameaçadas) e dos órgãos governamentais de direitos humanos. Nesse as- pecto, apresentou uma inovação social que foi reconhecida pelo governo estadual como alternativa de política, qual seja, o Banco de Dados Sobre Violência: Perfil dos Homicídios no ES, instrumentalizado na política de segurança pública (Dowbor; Carlos; Albuquerque, 2018). Baseado em fontes jornalísticas diversificadas, a metodologia do banco de dados foi desenvolvida pelo MNDH, CDDH-Serra e Navi-Ufes, com relatórios anuais de 1994 a 2000. A decisão de incorporação na administração pública ocorreu em 1997, com a criação do Núcleo de Direitos Humanos $(\mathrm{NDH})$ vinculado à Secretaria Estadual de Justiça e Cidadania (Sejuc). Em 2004, o banco de dados foi convertido no Centro Integrado Operacional de Defesa Social (Ciodes), um marco na instrumentalização da política de segurança pública. O Ciodes consiste num banco de dados integrado de informações criminais no governo estadual, agregando as fontes dos órgãos da segurança pública como Polícia Militar, Polícia Civil, Corpo de Bombeiros, Guarda Civil Municipal de Vitória, Secretaria de Justiça, Polícia Rodoviária Federal e, em algumas situações, Secretaria Estadual de Saúde (Sesa). A campanha também influenciou outras agendas e decisões relativas à burocracia governamental e aos instrumentos de política pública, exemplificadas pela criação: do Núcleo de Direitos Humanos (NDH/Sejuc); do Conselho Estadual de Direitos Humanos (CEDH), em 1995 (Lei $n^{0}$ 5.165); e do Programa de Proteção de Vítimas e Testemunhas Ameaçadas (Provita), em 1999 (Lei $\mathrm{n}^{\circ}$ 9.807). Na etapa de implementação da política, a pesquisa apontou a participação de organizações da sociedade civil em órgãos colegiados, como o CEDH, e a gestão de programas de proteção e promoção dos direitos humanos - especialmente o Provita, criado como instrumento de enfrentamento à criminalidade e à impunidade, oferecendo proteção às testemunhas, vítimas ou réus-colaboradores de processos jurídicos.

Por sua vez, a Campanha Contra a Violência no Sistema Prisional (2003-2012) introduziu na agenda pública estadual a pauta da 
tortura institucional nas unidades prisionais. Apresentou como alternativas os programas de proteção e promoção aos direitos humanos e o desenho participativo para órgãos estaduais de monitoramento das torturas e tratamentos cruéis nas prisões e unidades de internação socioeducativa. A campanha influenciou a decisão política de reestruturação da infraestrutura dos presídios, estabelecimentos de prisão provisória e unidades socioeducativas, em 2010, tais como: desativação das celas contêineres; reforma das Unis e a construção de novas unidades; redução da lotação nos DPJs; e construção de CDPs e centros de triagem (Justiça Global et al., 2011). Tais decisões governamentais foram resultantes de medidas cautelares ao Estado brasileiro, interpostas por organismos internacionais de direitos humanos (ONU e OEA), em ação coordenada do movimento de direitos humanos e organizações internacionais de direitos humanos como Justiça Global e Conectas, durante a campanha. A campanha influenciou ainda decisões políticas relativas à burocracia governamental, como a criação de órgãos de direitos humanos: o Comitê Estadual para a Prevenção e Erradicação da Tortura (Cepet), em 2004, formalizado pela Lei $\mathrm{n}^{\circ} 10.006$ (2013); a Subsecretaria de Direitos Humanos acoplada à Secretaria Estadual de Assistência Social e Direitos Humanos (2011); e a SEDH, em 2016. Resta destacar a influência do movimento de direitos humanos na decisão gover¿ี namental de elaboração do Plano Estadual de i. Direitos Humanos (PEDH) e do Plano Estadual $\stackrel{\Xi}{g}$ de Educação em Direitos Humanos (PEEDH), ช no âmbito do PNDH-III. Por fim, as campanhas ণิ das décadas de 1990 e 2000 influenciam a im-

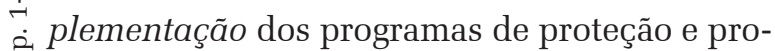
लं moção dos direitos humanos; além do Provita,

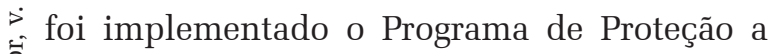
Crianças e Adolescentes Ameaçados de Morte (PPCAAM), em 2003 (Decreto $\mathrm{n}^{\circ}$ 6.231/2007), e o Programa de Proteção aos Defensores de Direitos Humanos (PPDDH), em 2005 (Lei $\mathrm{n}^{0}$ 8.233/2005), executados por organizações do movimento social. A criação desses órgãos públicos e colegiados, e de planos e programas engendrou capacidades estatais na burocracia governamental em vista da política de Direitos Humanos (Carlos, 2021). ${ }^{10}$

O movimento da criança e adolescente, na Campanha pelo Fim da Febem (1995-2007), com dimensão estadual, tem importante participação de organizações municipais, nacionais e mesmo internacionais. Essa Campanha tem consequências nas diversas fases da política setorial DCA, no subsetor de políticas socioeducativas com privação de liberdade. O movimento coloca na agenda municipal, estadual e nacional o fim do sistema menorista representado pela Febem (SP). Essa agenda se concretizou nas pautas dos Conselhos de Defesa dos Direitos da Criança e Adolescente, nos três níveis da federação, na mídia estadual e nacional, por meio das repercussões da CPI da Febem, e numa pauta nacional para a elaboração e criação do Sistema Nacional de Atendimento Socioeducativo (Sinase).

O movimento e seus aliados elaboraram alternativas para a política socioeducativa de internação por meio de sugestões que se converteram em resoluções dos Conselhos municipal (CMDCA), estadual (Condeca) e nacional (Conanda). Apresentaram também alternativas que resultaram nas orientações definidas pela CPI da Febem, pois suas resoluções definiram diretrizes para o "fim da Febem" e para a criação de um sistema fundado no paradigma garantista. Num nível mais amplo, as organizações do movimento integraram a elaboração participativa, ocorrida por meio de seminários em todo o país, das alternativas de política expressas nas diretrizes nacionais que constam na Resolução do Conanda (119/2006) e na Lei federal $n^{\circ} 12.594 / 2012$ sobre o Sinase, e nos Planos Decenais socioeducativos em todos os níveis. Sua influência nos momentos de decisão política se nota pela inclusão de algumas ${ }^{10}$ Para mais informações sobre as consequências do MDH-ES sobre a formulação e implementação da política pública, ver Carlos (2021), em que é demonstrado, em complemento, que esses resultados consistem num processo de institucionalização de direitos que configura encaixes institucionais e domínios de agência. 
de suas pautas em normativas da política como a Lei de criação da Fundação Casa e seu Estatuto, bem como nas Resoluções do Conanda, na Lei do Sinase e nos Planos Decenais.

O movimento da criança e adolescente, na Campanha pela municipalização da política socioeducativa em meio aberto (1999-2010), teve uma dimensão municipal. Os efeitos desta Campanha podem ser percebidos ao longo de distintos momentos. Embora a municipalização e o meio aberto já estivessem na agenda nacional, em decorrência de campanhas anteriores (na $\mathrm{CF} / 88$, no ECA, na PNAS, na Loas e na normativa de tipificação dos serviços socioassistenciais da PNAS), em São Paulo, essa campanha, em seu momento inicial, incide fortemente na agenda municipal.

Paralelamente, o movimento DCA, por meio de uma de suas organizações, a Pastoral do Menor desenvolveu a Liberdade Assistida Comunitária (LAC), uma inovação social que foi origem da elaboração de uma alternativa metodológica para a política em meio aberto (Dowbor; Carlos; Albuquerque, 2018). A especificação de uma alternativa para a política municipal resgata essa inovação metodológica e a sistematiza por meio de uma Comissão Interinstitucional constituída pelo movimento e por órgãos públicos. Essa alternativa, denominada Projeto-Piloto, é aprovada em dezembro de 2004.

A campanha sofre, no entanto, um revés político, e o Projeto-Piloto é revogado. O movimento retoma o processo de elaboração e especificação de alternativas para a política por meio dos Conselhos (CMDCA e Comas) e de GTs criados conjuntamente com a Secretaria Municipal. Resultados parciais aparecem nas decisões políticas representadas pelas Porta-

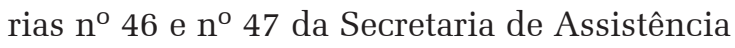
e Desenvolvimento Social (SMADS), em 2010 e, mais tarde, em 2014, com o Plano Decenal Socioeducativo de São Paulo.

A influência do movimento na implementação da política socioeducativa em meio aberto aparece ao longo de toda a Campanha, quando executa o atendimento socioeducativo de LAC e Prestação de Serviço Comunitário (PSC) por intermédio de ONGs (Serviços MSE/ MA), o que lhes serve de insumo para a proposição de alternativas.

No caso das campanhas do movimento da criança e adolescente, o estudo revela a presença de efeitos em todas as fases do ciclo de políticas, resultando na criação de normativas e legislações, órgãos e instituições, planos e projetos que impulsionam as capacidades estatais no setor. No entanto, na campanha 1 , não se nota incidência do movimento na implementação da política. O subsetor da política socioeducativa com privação de liberdade (em meio fechado) tem menor influência da sociedade civil, especialmente das organizações do movimento, que são muito críticas aos modelos implementados. Já no meio aberto, o movimento participa da implementação antes, durante e depois da Campanha. Essa participação é permeada de conflitos. Os coordenadores das ONGs executoras são mais solidários às regras dos convênios e os trabalhadores técnicos mais engajados no movimento, na busca da implementação do ECA.

No movimento de saúde, a Campanha pelo Financiamento da Saúde Pública (20032012) como um todo se desenrolou na esfera do Poder Legislativo e em torno de duas etapas primordiais: a formulação de alternativas que, neste caso, significava a elaboração de projetos de leis, e a tomada de decisões que ocorriam nos momentos de votações. Assim, pôde-se averiguar que o movimento foi capaz de submeter os projetos de seu interesse por meio de deputados que eram ativistas ou aliados (o Projeto de Lei Complementar n ${ }^{0}$ 1/2003 do deputado Roberto Gouveia e o Projeto de Lei $n^{\circ} 306 / 2008$ do senador Tião Viana). No entanto, nos momentos de decisão, e apesar das táticas de mobilização institucional e extrainstitucional, não conseguiu formar ou aproveitar a maioria do governo no congresso para a aprovação de uma lei que refletisse todos os seus objetivos: a Lei Complementar $\mathrm{n}^{\mathrm{O}} 141$ de 2012, que encerra a campanha, não aprova uma fon- 
te especial e maior de recursos para o setor de saúde no nível federal, que era o objetivo central. Os únicos avanços propostos pela Lei vieram no sentido da definição do que são gastos de saúde e o aumento da participação do controle social nas questões de financiamento da saúde pública, considerados pelo movimento como vitórias menores.

Por fim, a Campanha pela Formação de Recursos Humanos para Saúde Pública (19972001) abrangeu três etapas do ciclo de política, a de formulação de alternativas, da decisão política e implementação. O movimento foi capaz de apresentar suas propostas aproveitando para isso o momento de abertura do Estado para a recepção de soluções, bem como acompanhou a elaboração das propostas, interferindo antes da decisão final de modo a influenciar o processo. No caso do curso de enfermagem, o movimento interferiu na composição da Comissão de Especialistas ao cargo do qual estava a responsabilidade de elaborar a proposta final, inserindo ativistas a favor da proposição do movimento. O que chama atenção, nos dois casos, é a presença e o acompanhamento sistemático pelo movimento na etapa da formulação de alternativas. Os ativistas trazem para dentro desse processo suas propostas e interferem quando veem suas propostas sendo alteradas por outros atores. A decisão final a respeito dos currículos contida no Parecer $\mathrm{n}^{\mathrm{o}}$ 1.133/2001, emitido em 7 de novembro pelo ন্ড Conselho Nacional de Educação (CNE) e sua CâN. mara de Ensino Superior, reflete as propostas do . movimento. Com base nessa institucionalização \& das diretrizes, os sanitaristas elaboraram a seguir จึ uma série de políticas públicas voltadas para a $\dot{2}$ implementação delas nos cursos de saúde. Numa लि articulação entre a Abem, a Rede Unida e a Organização Pan-Americana de Saúde (Opas), com a contribuição da Comissão Interinstitucional Nacional de Avaliação das Escolas Médicas (Cinaem), foi criado, em 2002, o Programa de Incentivo a Mudanças Curriculares em Cursos de Medicina (Promed) pelo Ministério da Saúde, que consistia em um sistema de incenti- vos financeiros às instituições acadêmicas que se dispusessem a adequar a formação profissional às necessidades do SUS. Com base no Promed, em seguida foi implementado o Programa Nacional de Reorientação da Formação Profissional em Saúde (Pró-Saúde) 1 e 2, que, além do incentivo financeiro às escolas de Medicina, incorporou o incentivo financeiro para os municípios que abrigassem as Escolas de Medicina participantes do programa e os que mantivessem programas de Residência Médica em Medicina de Família e Comunidade (Amaral, 2007), o que garantia o treinamento de jovens nos equipamentos públicos.

A descrição sintética dos efeitos políticos dos movimentos sociais segundo a tipologia de ciclo de políticas públicas é apresentada no Quadro 2, identificados nas etapas de formação de agenda, especificação de alternativa, tomada de decisão e implementação da política.

\section{CONCLUSÕES}

A pesquisa revela que movimentos sociais influenciam diferentes etapas do ciclo de políticas públicas, quais sejam, formação de agenda, especificação de alternativas, decisão e implementação, contribuindo com os recentes avanços da literatura especializada. Desse modo, os movimentos sociais produzem consequências não somente nas fases iniciais da política, mas também na implementação. Os resultados na política setorial incidem sobre órgãos da administração pública, colegiados, normativas, legislações, programas e planos. Os efeitos no ciclo de políticas e, por conseguinte, a criação de capacidades estatais e a institucionalização de direitos é a consequência política mais geral dos movimentos sociais em campanhas, mesmo nos casos de resultados parciais.

O estudo comparado de movimentos sociais engajados em campanhas de médio e longo prazo demonstrou que os atores acompanham todas as etapas do ciclo de políticas públicas, de 
Quadro 2 - Efeitos de campanhas de movimentos sociais, segundo a tipologia de ciclo de políticas (1990 e 2000)

\begin{tabular}{|c|c|c|c|c|c|}
\hline MS & Campanha & $\begin{array}{l}\text { Formação da } \\
\text { Agenda }\end{array}$ & $\begin{array}{l}\text { Especificação de Alterna- } \\
\text { tivas }\end{array}$ & Decisão & Implementação \\
\hline \multirow{10}{*}{ 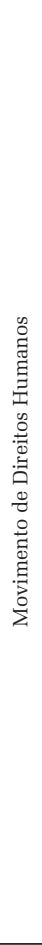 } & \multirow{5}{*}{$\begin{array}{l}\text { Impunidade e } \\
\text { corrupção }\end{array}$} & $\begin{array}{l}\text { Pauta combate ao } \\
\text { crime organizado. }\end{array}$ & & $\begin{array}{l}\text { Representação para fim de dissolu- } \\
\text { ção da SDLC; } \\
\text { aprovação da inclusão do ES na } \\
\text { CPI do Narcotráfico; instalação da } \\
\text { Missão Especial de Combate ao Cri- } \\
\text { me Organizado, que levou à prisão } \\
\text { de agentes públicos e a dissolução } \\
\text { da SDLC. }\end{array}$ & \\
\hline & & $\begin{array}{l}\text { Pauta segurança } \\
\text { pública e direitos } \\
\text { humanos. }\end{array}$ & $\begin{array}{l}\text { Banco de Dados Sobre a Vio- } \\
\text { lência: Perfil dos homicídios } \\
\text { no ES, visando a integração } \\
\text { de estatísticas criminais. }\end{array}$ & $\begin{array}{l}\text { Incorporação do Banco de Dados da } \\
\text { Violência nos órgãos de segurança } \\
\text { pública; criação do Ciodes. }\end{array}$ & \\
\hline & & $\begin{array}{l}\text { Pauta burocracia } \\
\text { pública de direitos } \\
\text { humanos. }\end{array}$ & & Criação do NDH & \\
\hline & & $\begin{array}{l}\text { Pauta órgãos cole- } \\
\text { giados de direitos } \\
\text { humanos. }\end{array}$ & $\begin{array}{l}\text { Participação da sociedade } \\
\text { civil. }\end{array}$ & Criação do CEDH (Lei n 5.165). & Participação colegiada no CEDH. \\
\hline & & $\begin{array}{l}\text { Pauta proteção e pro- } \\
\text { moção dos direitos } \\
\text { humanos. }\end{array}$ & $\begin{array}{l}\text { Ações de proteção de vítimas } \\
\text { e testemunhas ameaçadas. }\end{array}$ & Criação do Provita (Lei nº 9.807). & $\begin{array}{l}\text { Implementação do Provita por } \\
\text { organizações do movimento. }\end{array}$ \\
\hline & \multirow{5}{*}{$\begin{array}{l}\text { Violações no sis- } \\
\text { tema prisional }\end{array}$} & $\begin{array}{l}\text { Pauta tortura institu- } \\
\text { cional nas unidades } \\
\text { prisionais. }\end{array}$ & & $\begin{array}{l}\text { Reestruturação da infraestrutura dos } \\
\text { presídios e Unes. }\end{array}$ & \\
\hline & & $\begin{array}{l}\text { Pauta proteção e pro- } \\
\text { moção dos direitos } \\
\text { humanos. }\end{array}$ & $\begin{array}{l}\text { Ações de proteção de crian- } \\
\text { ças e adolescentes e ativistas } \\
\text { ameaçados. }\end{array}$ & $\begin{array}{l}\text { Criação do PPCAAM (Decreto } \\
\left.\mathrm{n}^{\circ} 6.231 / 2007\right) \text { e PPDDH (Lei } \\
\left.\mathrm{n}^{\circ} 8.233 / 2005\right) .\end{array}$ & $\begin{array}{l}\text { Implementação do PPCAAM e } \\
\text { do PPDDH por organizações do } \\
\text { movimento. }\end{array}$ \\
\hline & & $\begin{array}{l}\text { Pauta órgãos cole- } \\
\text { giados de direitos } \\
\text { humanos. }\end{array}$ & $\begin{array}{l}\text { Participação da sociedade } \\
\text { civil. }\end{array}$ & $\begin{array}{l}\text { Criação do Cepet (Lei } \\
\left.\mathrm{n}^{\circ} 10.006 / 2013\right) .\end{array}$ & Participação colegiada no Cepet. \\
\hline & & $\begin{array}{l}\text { Pauta normativas de } \\
\text { direitos humanos. }\end{array}$ & & Elaboração do PEDH e PEEDH. & \\
\hline & & $\begin{array}{l}\text { Órgãos de direitos } \\
\text { humanos. }\end{array}$ & & Criação da SEDH & \\
\hline \multirow{7}{*}{ 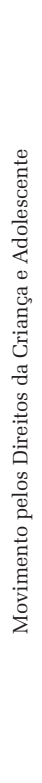 } & \multirow{3}{*}{ Fim da Febem } & $\begin{array}{l}\text { Pauta municipal e } \\
\text { estadual pelo fim da } \\
\text { Febem } \\
\text { no CMDCA e } \\
\text { Condeca. }\end{array}$ & $\begin{array}{l}\text { Resoluções no CMDCA e } \\
\text { Condeca. }\end{array}$ & \multirow{2}{*}{$\begin{array}{l}\text { Aprovação da criação da CPI da } \\
\text { Febem. } \\
\text { Decreto de criaçãa da Fundação } \\
\text { CASA e aprovação de seu Estatuto. }\end{array}$} & \\
\hline & & Fim da Febem. & $\begin{array}{l}\text { Orientações definidas pela } \\
\text { CPI sobre a Febem. }\end{array}$ & & \\
\hline & & $\begin{array}{l}\text { Pauta nacional de } \\
\text { criação do Sinase. }\end{array}$ & $\begin{array}{l}\text { Participação da sociedade } \\
\text { civil na elaboração das dire- } \\
\text { trizes nacionais (Resoluções e } \\
\text { Lei do Sinase). }\end{array}$ & $\begin{array}{l}\text { Aprovação das Resoluções (Conan- } \\
\text { da), da Lei do Sinase e dos Planos } \\
\text { Decenais. }\end{array}$ & \\
\hline & \multirow{4}{*}{$\begin{array}{c}\text { Municipalização } \\
\text { da política so- } \\
\text { cioeducativa em } \\
\text { meio aberto. }\end{array}$} & $\begin{array}{l}\text { Pautas da municipa- } \\
\text { lização na Constitui- } \\
\text { ção e no ECA, } \\
\text { na Loas, na PNAS } \\
\text { e tipificação de } \\
\text { serviços socioassis- } \\
\text { tenciais. }\end{array}$ & $\begin{array}{l}\text { Elaboração de metodologia } \\
\text { de ação com adolescentes } \\
\text { na LAC. }\end{array}$ & & $\begin{array}{l}\text { Implementação de metodologia } \\
\text { de ação com adolescentes e } \\
\text { instrumentos de monitoramento } \\
\text { na LAC. }\end{array}$ \\
\hline & & $\begin{array}{l}\text { Pauta da descentrali- } \\
\text { zação e municipali- } \\
\text { zação do meio aberto } \\
\text { no Plas, conselhos e } \\
\text { Conferência. }\end{array}$ & $\begin{array}{l}\text { Elaboração do Plano-Piloto } \\
\text { por comissão interinstitu- } \\
\text { cional. }\end{array}$ & $\begin{array}{l}\text { Aprovação do Projeto-Piloto, diretri- } \\
\text { zes municipais. }\end{array}$ & $\begin{array}{l}\text { Execução do atendimento } \\
\text { socioeducativo de LA e PSC por } \\
\text { meio de ONGs conveniadas com } \\
\text { a Febem e com a prefeitura no } \\
\text { Projeto-Piloto. }\end{array}$ \\
\hline & & \multirow{2}{*}{$\begin{array}{l}\text { Pautas da municipa- } \\
\text { lização no CMDCA, } \\
\text { Comas e SMADS. }\end{array}$} & \multirow{2}{*}{$\begin{array}{l}\text { Elaboração de Resoluções do } \\
\text { CMDCA e Comas com diretri- } \\
\text { zes municipais da Política de } \\
\text { Meio Aberto. }\end{array}$} & $\begin{array}{l}\text { Portarias municipais } \mathrm{n}^{\circ} 46 \text { e } \mathrm{n}^{\circ} 47 \\
\text { de regulação da política municipal }\end{array}$ & \multirow{2}{*}{$\begin{array}{l}\text { Execução do atendimento socio- } \\
\text { educativo de LA e PSC por meio } \\
\text { de ONGs conveniadas com a } \\
\text { prefeitura (Serviços MSE/MA). }\end{array}$} \\
\hline & & & & $\begin{array}{l}\text { Política Municipal de Meio Aberto, } \\
\text { que resultou no Plano Decenal. }\end{array}$ & \\
\hline \multirow{3}{*}{ 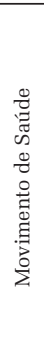 } & \multirow[b]{2}{*}{$\begin{array}{l}\text { Financiamento } \\
\text { da saúde pública. }\end{array}$} & & $\begin{array}{l}\text { Projeto de Lei Complemen- } \\
\operatorname{tar} \mathrm{n}^{\circ} 1 / 2003 \text { do deputado } \\
\text { Roberto Gouveia. }\end{array}$ & Projeto arquivado. & \\
\hline & & & $\begin{array}{l}\text { Projeto de Lei 306/2008 do } \\
\text { senador Tião Viana. }\end{array}$ & $\begin{array}{l}\text { Aprovação da Lei Complementar } \\
\mathrm{n}^{\circ} 141 \text { de } 2012 \text { sobre controle social } \\
\text { do orçamento de saúde e de defini- } \\
\text { ção de gastos em saúde. }\end{array}$ & \\
\hline & $\begin{array}{l}\text { Recursos huma- } \\
\text { nos para saúde } \\
\text { pública. }\end{array}$ & & $\begin{array}{l}\text { Elaboração de proposta } \\
\text { curricular para seis cursos } \\
\text { superiores em saúde entregue } \\
\text { ao MEC. }\end{array}$ & $\begin{array}{l}\text { Currículos aprovados pelo MEC } \\
\text { de acordo com a proposta do } \\
\text { movimento. }\end{array}$ & $\begin{array}{l}\text { Implementação do Programa } \\
\text { de Incentivo a Mudanças } \\
\text { Curriculares em Cursos de Me- } \\
\text { dicina (Promed) e do Programa } \\
\text { Nacional de Reorientação da } \\
\text { Formação Profissional em Saúde } \\
\text { (Pró-Saúde) } 1 \text { e } 2 \text {. }\end{array}$ \\
\hline
\end{tabular}


modo a ampliar sua influência e transformar seus clamores em capacidades estatais. Os movimentos vão além da identificação e visibilização de dado problema no debate público ou na formação de agenda. Detectam e interpretam as janelas de oportunidades, que não raramente permitem a ascensão de suas reivindicações à agenda de governo, para sugerir e publicizar suas propostas de solução. Nessa etapa de especificação de alternativas, chama atenção o intenso engajamento dos atores para formalizar, apresentar, defender e reapresentar suas ideias em disputa com outros atores ou em processos de longa duração, como é o caso dos trâmites dos projetos no Poder Legislativo. A consequência direta disso é sua proposta estar contemplada enquanto alternativa por quem toma a decisão final. Em termos da decisão, observamos uma diversidade de instrumentos aprovados que vão desde a criação de órgãos na burocracia pública, passando pela aprovação de políticas municipais e estaduais ou de leis ou de decisões vinculantes emitidas por órgãos competentes do Poder Executivo. Os atores também influenciam na fase de implementação da política defendida pelo movimento, como observamos nos setores de direitos humanos, da criança e adolescente e de saúde, sendo, nos dois primeiros casos, por meio da execução de programas e projetos governamentais. Trata-se de etapa mais raramente estudada pelos pesquisadores de movimentos sociais. O engajamento de movimentos ¿ิ nela mostra que a implementação de fato é uma 仓 etapa complexa e que, em si, pode conter uma série de novas decisões que, se não acompanhaช das, pode resultar em algo distante da decisão ชิ inicialmente aprovada. Em termos de agenda de $\therefore$ pesquisa futura, nos parece promissor acompaङु nhar os atores de movimentos na etapa de im-

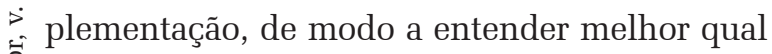
é o papel e a importância de movimentos nessa fase do ciclo de políticas. Importa também aprofundar como o maior ou menor grau de institucionalização da política em questão possibilita ou impede a participação do movimento na implementação da política.
Os repertórios, as coalizões e capacidades estatais são condições significativas que agem de modo combinado na produção de resultados nas políticas públicas. Conforme assinalado pela literatura, as condições podem se combinar de diferentes maneiras para produzir efeitos nas políticas. O estudo das seis campanhas apontou o uso de repertórios tanto extrainstitucionais quanto institucionais, de caráter conflitivo e cooperativo-conflitual o que coaduna com o perfil dos três movimentos engajados, todos históricos, com legado de experiências pretéritas e aprendizados nas interações com o Estado e com expertise em setores de políticas específicas. A presença de coalizões com atores e instituições do Estado também se destaca nas campanhas e, em três delas, chamam atenção as alianças internacionais.

Constitui um próximo desafio tanto analisar as combinações dessas condições em cada campanha quanto averiguar sua combinação em relação aos efeitos específicos em cada etapa do ciclo de políticas públicas. Um achado contraintuitivo está nos efeitos na etapa de implementação nas políticas menos institucionalizadas, em que as capacidades estatais são mais frágeis e requerem estruturação, como na política de direitos humanos e de criança e adolescente. Comparativamente, foi nas políticas com menor grau de institucionalização que ocorreu a participação dos movimentos na etapa de implementação por meio da execução de programas governamentais por organizações civis.

Recebido para publicação em 25 de agosto de 2019 Aceito em 16 de agosto de 2021

\section{REFERÊNCIAS}

ABERS, R. N.; SERAFIM, L.; TATAGIBA, L. F. Repertórios de interação Estado-sociedade em um Estado heterogêneo: a experiência da era Lula. Dados, Rio de Janeiro, v. 57, n. 2, p. 325-357, 2014.

ALONSO, A. O abolicionismo como movimento social. Novos Estudos Cebrap, São Paulo, n. 100, p. 115-137, 2014.

AMENTA, E.; CAREN, N., CHIARELlO, E.; SU, Y. The 
political consequences of social movements. Annual Review of Sociology, v. 36, p. 287-307, 2010.

BANASZAK, L. A. The women's movement inside and outside the State. Cambridge: Cambridge University Press, 2010.

BOSI, L. Incorporation and democratization: the long-term process of institutionalization of the Northern Ireland Civil Rights Movement. In: BOSI, L; GIUGNI, M; UBA, K. (org.). The consequences of social movements. Cambridge: Cambridge University Press, 2015. p. 338-360.

BOSI, L.; GIUGNI, M; UBA, K. The consequences of social movements. Cambridge: Cambridge University Press, 2016.

CAPELLA, A. C. N. Formulação de políticas. Brasília, DF: Enap, 2018.

CARLOS, E. Mudanças e continuidades no movimento de direitos humanos: padrões organizacionais, relacionais e discursivos. Opinião Pública, Campinas, v. 20, n. 3, p. 450479, 2014.

. Movimentos sociais e instituições participativas: $\overline{\text { efeitos }}$ do engajamento institucional no contexto póstransição. Belo Horizonte: Fino Traço, 2015.

Cooperação e conflito na relação movimentos

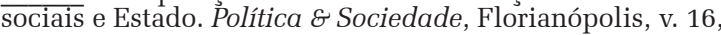
n. 35, p. 321-350, 2017.

Movimentos sociais e políticas públicas consequências na Política Nacional de Direitos Humanos. Dados, Rio de Janeiro, v. 64, n. 4, p. 1-41, 2021.

CARLOS, E.; DOWBOR, M.; ALBUQUERQUE, M. C. Movimentos sociais e seus efeitos nas políticas públicas: balanço do debate e proposições analíticas. Civitas, Porto Alegre, v. 17, n. 2, p. 360-378, 2017.

DAGNINO, E. (org.). Anos 90: política e sociedade no Brasil. São Paulo: Brasiliense, 1994.

DIANI, M. Introduction: social movements, contentious actions, and social networks: 'from metaphor to substance'? In: DIANI, M.; MCADAM, D. (org.). Social movements and networks. Relational approaches to collective action. Oxford: Oxford University Press, 2003. p. 1-18.

DOWBOR, M. Arte da institucionalização: estratégias de mobilização dos sanitaristas (1974-2006). 2012. Tese (Doutorado em Ciências Política) -Universidade de São Paulo, São Paulo, 2012.

DOWBOR, M.; CARLOS, E.; ALBUQUERQUE, M. C. As origens movimentistas de políticas públicas: proposta analítica aplicada às áreas de criança e adolescente, direitos humanos e saúde. Lua Nova: Revista de Cultura e Política, São Paulo, n. 105, p. 47-80, 2018.

EARL, J. The cultural consequences of social movements. In: SNOW, D; SOULE, S; KRIESI, H (org.). The blackwell companion to social movements. Oxford: Blackwell, 2004. p. 508-530.

ESCOREL, S. Reviravolta na saúde: origem e articulação do movimento sanitário. Rio de Janeiro: Fiocruz, 1998.

GAMSON, W. The strategy of social protest. Belmont: Wadsworth, 1990.

GERRING, J. Case study research: principles and practices. Cambridge: Cambridge University Press, 2007.

GIUGNI, M. Political, biographical, and cultural consequences of social movements. Sociology Compass, [s. l.], v. 2, n. 5, p. 1582-1600, 2008.

GIUGNI, M.; YAMASAKI, S. The policy impact of social movements: a replication through qualitative comparative analysis. Mobilization: An International Quarterly, Chapel Hill, v. 14, n. 4, p. 467-484, 2009.

GIUGNI, M.; MCADAM, D.; TILLY, C. How social movements matter. Minneapolis: Minnesota Press, 1999.
GURZA LAVALLE, A.; CARLOS, E.; DOWBOR, M.; SZWAKO, J. Movimentos sociais e institucionalização: políticas sociais, raça e gênero no Brasil pós-transição. Rio de Janeiro: Eduerj, 2019.

JUSTICA GLOBAL; CONECTAS DIREITOS HUMANOS CENTRO DE DEFESA DOS DIREITOS HUMANOS; CONSELHO ESTADUAL DE DIREITOS HUMANOS. Violações de direitos humanos no sistema prisional do Espírito Santo: atuação da sociedade civil. Rio de Janeiro, 2011.

KINGDON, J. W. Agendas, alternatives and public policies. New York: Harper Collins, 1995.

MACIEL, D. Ação coletiva, mobilização do direito e instituicões políticas: o caso da campanha da Lei Maria da Penha. Revista Brasileira de Ciências Sociais, São Paulo, v. 26, n. 77, p. 97-112, 2011.

MAHONEY, J.; THELEN, K. Explaining institutional change: ambiguity, agency, and power. Cambridge: Cambridge University Press, 2010.

MOVIMENTO NACIONAL DE DIREITOS HUMANOS. Relatório final da Campanha Nacional Permanente de Combate à Tortura e à Impunidade. Rio de Janeiro, 2003.

PICCIO, D. The impact of social movements on political parties. In: BOSI, L; GIUGNI, M; UBA, K. (org.). The consequences of social movements. Cambridge: Cambridge University Press, 2016. p. 263-284.

PIRES, R.; GOMIDE, A. Governança e capacidades estatais: uma análise comparativa de programas federais. Revista de Sociologia e Política, Curitiba, v. 24, n. 58, p. 121-143, 2016.

POLLETTA, F.; JASPER, J. Collective identity and social movements. Annual Review of Sociology, San Mateo, v. 27, p. 283-305, 2001

ROOTES, C. Environmental protest in Western Europe. Oxford: Oxford University Press, 2004.

ROOTES, C.; NULMAN, E. The impacts of environmental movements. In: DELLA PORTA, D.; DIANI, M. (org.). The Oxford handbook of social movements. Oxford: Oxford Press, 2015. p. 729-742.

SABATIER, P. A.; WEIBLE, C. M. The advocacy coalition framework: innovations and clarifications. In: SABATIER, P. A. (org.). Theories of policies process. Boulder, Westview Press, 2007. p. 189-222.

SECCHI, L. Políticas públicas: conceitos, esquemas de análise, casos práticos. São Paulo: Cengage Learning, 2010.

SOULE, S.; KING, B. The stages of the policy process and the equal rights amendment, 1972-1982. American Journal of Sociology, Chicago, v. 111, p. 1871-1909, 2006.

SOUZA, C. Políticas públicas: uma revisão da literatura. Sociologias, Porto Alegre, v. 8, n. 16, p. 20-45, 2006.

TATAGIBA, L.; TEIXEIRA, A. C. Efeitos combinados dos movimentos de moradia sobre os programas habitacionais autogestionários. Sociologia e Política, Florianópolis, v. 24 n. 58, p. 85-102, 2016

TILLY, C. Regime and repertoire. Chicago: University of Chicago Press, 2006.

Movimentos sociais como política, Revisto Brasileira de Ciência Política, Brasília, DF, n. 3, p. 133-160, 2010. 


\section{EFFECTS OF SOCIAL MOVEMENTS ON PUBLIC POLICY CYCLE}

\author{
Euzeneia Carlos \\ Monika Dowbor \\ Maria do Carmo Albuquerque
}

This comparative study involving the human rights, child and adolescent and health sectors analyzes the political effects of social movements on public policy cycle. The empirical research compares six campaigns over two decades (1990 and 2000), triggered by related social movements by means of documents and interviews with activists. We use a correlational approach to measure the political effects, that is, the correspondence between the campaign demands and the outcomes in sectoral politics. We classify the political effects associated with movement campaigns into the public policy cycle typology. Our main contribution is to show the influence of social movements in the different stages of the policy cycle, namely: agenda setting, specification of alternatives, decision, and implementation, whose effects are produced by conditions such as repertoires, coalitions, and state capabilities.

Keywords: Social Movements. Public Policy. Mots-clés: Mouvements Sociaux. Politiques

Political Outcomes. Human Rights; Children and Publiques. Effets Politiques. Droits de l'Homme.

\section{EFFETS DES MOUVEMENTS SOCIAUX SUR LE CYCLE DES POLITIQUES PUBLIQUES}

\author{
Euzeneia Carlos \\ Monika Dowbor \\ Maria do Carmo Albuquerque
}

Cette étude comparative impliquant les secteurs des droits de l'homme, de l'enfance e de l'adolescence et de la santé analyse les effets politiques des mouvements sociaux sur le cycle des politiques publiques. La recherche empirique compare six campagnes sur deux décennies (1990 et 2000), déclenchées par des mouvements sociaux connexes, par le biais des documents et d'interviews avec des militants. Nous utilisons une approche corrélationnelle pour mesurer les effets politiques, c'est-à-dire la correspondance entre les demandes de la campagne et les résultats dans la politique sectorielle. On classe les effets politiques associé aux campagnes dans la typologie des cycles de politique publique. Notre principale contribution est de montrer l'influence des mouvements sociaux dans les différentes étapes du cycle politique, à savoir : la définition de l'agenda, la spécification des alternatives, la décision et la mise en œuvre, dont les effets sont produits par des conditions telles que les répertoires, les coalitions et les capacités de l’État. 
Euzeneia Carlos - Professora do Programa de Pós-Graduação em Ciências Sociais da Universidade Federal do Espírito Santo (UFES), coordenadora do Núcleo Participação e Democracia (NUPAD) e pesquisadora do Centro Brasileiro de Análise e Planejamento (Cebrap). Pós-doutora pelo Cebrap, doutora em Ciência Política pela Universidade de São Paulo (USP) e mestre em Planejamento Urbano e Regional pela Universidade Federal do Rio de Janeiro (IPPUR/UFRJ). Atua na área de Ciência Política, nos temas: participação, movimentos sociais, sociedade civil, democracia participativa e políticas públicas. Publicou diversos artigos em periódicos e quatro livros: Movimentos sociais e institucionalização: políticas sociais, gênero e raça no Brasil pós-transição, coautoria com Adrian Gurza Lavalle, Monika Dowbor e José Szwako (EdUERJ, 2019); Movimentos sociais e instituições participativas: efeitos do engajamento institucional no contexto pós-transição (Fino Traço, 2015); Controle social e política redistributiva no orçamento participativo (EdUFES, 2015 e 2007) e; Sociedade civil e políticas públicas: atores e instituições no Brasil contemporâneo, coautoria com Wagner de Melo Romão e Osmany Porto de Oliveira (Argos, 2014).

Monika Dowbor - Professora do Programa de Pós-Graduação em Ciências Sociais da Universidade do Vale do Rio dos Sinos (Unisinos) e pesquisadora do Centro Brasileiro de Análise e Planejamento (Cebrap). Possui formação em Ciências Sociais, com doutorado em Ciência Política. Trabalha com pesquisas enquadradas pelas Teorias de Movimentos Sociais, Teorias e Abordagens de Políticas Públicas e pelo Institucionalismo Histórico, com ênfases nos seguintes temas: interações socioestatais, organizações da sociedade civil, movimentos sociais, organizações de movimentos sociais, efetividade de movimentos sociais, políticas públicas, avaliação de políticas públicas, entre outros. Publicou diversos artigos em periódicos e o livro Movimentos sociais e institucionalização: políticas sociais, gênero e raça no Brasil pós-transição, coautoria com Adrian Gurza Lavalle, Euzeneia Carlos e José Szwako (EdUERJ, 2019).

Maria do Carmo Albuquerque - Doutora em Integração da América Latina pela Universidade de São Paulo (PROLAM/USP) e mestre em Ciência Política pela Universidade Estadual de Campinas (Unicamp). É pesquisadora do Núcleo Democracia e Ação Coletiva do Centro Brasileiro de Análise e Planejamento (NDAC-CEBRAP). Atuou como pesquisadora e docente no Mestrado Profissional Adolescente em Conflito com a Lei (Unian/SP) e no Instituto Pólis. Atua principalmente nos seguintes temas: movimentos sociais, sociedade civil, participação e controle social sobre políticas públicas, com ênfase em orçamentos participativos, conselhos gestores e políticas públicas de direitos do adolescente em conflito com a lei. Entre suas publicações destacam-se artigos em periódicos especializados e livros organizados como “La construcción democrática desde abajo en el Cono Sur”. São Paulo: Instituto Pólis (2004). 
